\title{
A excepcionalmente modesta indumentária dos
} Estudos Americanos

A propósito do Colóquio Internacional de Estudos Americanos "America Where?" (Coimbra, 12-13 de Junho de 2009)

João Paulo Guimarães

\section{CpenEdition}

\section{Journals}

Edição electrónica

URL: http://journals.openedition.org/rccs/532

DOI: $10.4000 /$ rccs.532

ISSN: $2182-7435$

\section{Editora}

Centro de Estudos Sociais da Universidade de Coimbra

Edição impressa

Data de publição: 1 junho 2009

Paginação: 185-187

ISSN: 0254-1106

Refêrencia eletrónica

João Paulo Guimarães, «A excepcionalmente modesta indumentária dos Estudos Americanos », Revista Crítica de Ciências Sociais [Online], 85 | 2009, posto online no dia 01 outubro 2012, consultado o 15 setembro 2020. URL : http://journals.openedition.org/rccs/532 


\section{Noticiário}

\section{A excepcionalmente modesta indumentária dos Estudos Americanos. A propósito do Colóquio Internacional de Estudos Americanos “America Where?" (Coimbra, 12-13 de Junho de 2009)}

Onde está a "América” ? Esta é uma pergunta que o campo interdisciplinar dos Estudos Americanos já há muito tempo procura responder. Com as primeiras ideias a começar a surgir ainda antes da $2^{a}$ Grande Guerra, e, como tal, num momento anterior à consolidação da hegemonia global dos Estados Unidos, esta área de estudos foi sofrendo, até aos dias de hoje, toda uma diversidade de metamorfoses metodológicas, epistemológicas e ideológicas.

Num período ainda embrionário da disciplina, vários académicos provenientes das áreas da Literatura e da História uniram esforços no intuito de tentar encontrar a "América" no restrito repositório mitológico que consideravam ter colonizado a consciência de toda uma cultura. Assim sendo, o objecto de estudo destes Americanistas cingia-se a um conjunto de cenários utópicos subordinados a um ideal de abundância, como é o caso do Jardim do Éden (localizado "ao cimo da colina”) ou do mítico e "virginal” Far West, zona "selvagem" de fronteiras recicláveis que permitia o prolongamento ad aeternum do movimento penetrativo europeu de conquista territorial. Esta extraordinária geografia da mente era o sustento de um imaginário comum pelo menos já desde os tempos da chegada dos Puritanos à terra que viriam prenunciadoramente a baptizar com o nome de Nova Inglaterra.

Contudo, o trabalho levado a cabo por estes estudiosos, apologistas do carácter singular e excepcional da experiência americana, foi condenado pelas gerações que se seguiram - os "Novos Americanistas". Estes viram a investigação dos seus antecessores como algo simplista e unicamente aplicável às coordenadas socioculturais de um dos múltiplos grupos que povoavam o país: a elite de homens brancos de classe média, que desde sempre fora detentora do poder. Desde então, os Estudos Americanos têm vindo, progressivamente, a estender o seu campo de investigação no sentido de dar voz a um leque cada vez mais diversificado de minorias (étnicas, sexuais e raciais, por exemplo) cuja visibilidade sempre fora ofuscada pelo carácter omnipresente, omnipotente e, acima de tudo, tendenciosamente imparcial do discurso dominante.

Fruto deste imparável alargamento, tanto no que diz respeito aos intervenientes como aos objectos de estudo, tornou-se clara a multiplicação de "Américas" sobre as quais se ia teorizando. Uma delas passou, com efeito, a ser, num período bastante recente, a "América Transnacional". É, como tal, neste contexto que se insere o Colóquio Internacional de Estudos Americanos, sugestivamente intitulado "America Where?”, que teve lugar nos passados dias 12 e 13 de Junho na Faculdade de Letras da Universidade de Coimbra, com o objectivo de dar visibilidade ao novo programa de estudos de Doutoramento em Estudos Americanos desta instituição. Um distinto leque de académicos, oriundos dos Estados Unidos e de vários países europeus (Teresa Alves, professora da Universidade de Lisboa, era a única conferencista portuguesa), foi convidado a vir debater com 
o público nacional o estado da arte em termos dos estudos que se debruçam sobre esse tão camaleónico e trapaceiro espaço de interactividade que é a "América".

O que é, afinal de contas, ser "americano"? A questão da identidade nacional foi, com efeito, ubíqua durante todo o colóquio, especialmente por causa da sua particular relevância num contexto posterior aos ataques de 11 de Setembro. Este último veio mostrar aos americanos e ao mundo o carácter poroso e ficcional da narrativa de excepcionalidade e impenetrabilidade criada em torno do território que viria a simbolizar a "liberdade" e, acima de tudo, "o bem" que triunfa sempre sobre "o mal".

Amy Kaplan, docente da Universidade da Pensilvânia e ex-presidente da Associação Americana de Estudos Americanos, salientou, na sua intervenção, a qualidade imaginativa das narrativas nacionais, isto é, o modo como estas são construídas e "monumentalizadas" a posteriori dos eventos históricos, no sentido de homogeneizar identidades. A nacionalidade não é, como tal, algo que nasça connosco mas sim um papel cultural que aprendemos a dramatizar no palco do social. É esta concepção de identidade fluida e performativa que, aliás, foi ilustrada pelo magnífico cartaz publicitário (concebido pelo designer João Caldeira Carvalho) que deu a conhecer o formato do colóquio ao público e que mostra como a nacionalidade é, na verdade, uma questão de escolher qual a "roupa" que queremos combinar entre a pletora de possibilidades que temos à nossa disposição no restrito "guarda-vestidos identitário” que precede sempre a nossa existência. Daí o engenhoso trocadilho usado para nomear o colóquio, que situa a identidade do sujeito num espaço de maleabilidade poética que faz coincidir o lugar imaginado ("where") com a indumentária do actor ou actriz ("wear").
Apesar de tudo, a identificação com uma nacionalidade (e com um Estado, como acrescentou Ana Manzanas, da Universidade de Salamanca) funciona, de facto, como um requerimento que o indivíduo é forçado a preencher para que a sua existência seja reconhecida na sociedade em que se movimenta. Essa necessidade de conformação com os moldes identitários pré-estabelecidos, e subsequente obliteração de toda uma pluralidade de interfaces de subversão identitária, leva-nos à intervenção de George Hutchinson, professor da Universidade do Indiana. Este trabalhou a temática da raça enquanto fatalidade, nas duas acepções complementares que a palavra tem em português, isto é, enquanto destino (algo que não podemos transcender) e enquanto memento mori (algo que nos obriga a reconhecer a nossa fragilidade). Ainda hoje em dia continua a ser privilegiada uma distribuição racial binária e bicromática que desencoraja o jogo de identidades híbridas, cada vez mais visíveis e imperativas no tecido social americano, apesar da abolição da chamada "one drop rule", que muito contribuiu para a naturalização e perpetuação destas divisões.

Também o crítico holandês Rob Kroes (ex-presidente da Associação Europeia de Estudos Americanos) se reportou ao modo como a miscigenação de culturas é silenciada em prol da coagulação de identidades nacionais homogéneas. $\mathrm{Na}$ sua comunicação, Kroes problematizou a americanidade da cultura americana ao referir-se às suas origens europeias. Vistas a partir do prisma da intertextualidade e da derivação, as recorrentes disputas culturais entre os EUA e a Europa (como se esta tivesse uma única cultura) apresentam-se como algo visivelmente irónico e patético. A este respeito, Jonathan Auerbach, professor da Universidade de Maryland-College Park, chamou a atenção para a "origem” francesa 
do western americano, como um entre muitos dos pontos em que a cultura de massas dos EUA foi informada por ideais e autores europeus. As birras e amuos relativamente à Origem e à Originalidade tornam-se, então, um eterno castigo auto-imposto. Há, por esta razão, uma necessidade de "contradizer" a holográfica Voz paternal que informa a Nação Americana, ou seja, uma imprescindibilidade de dizer "não" e, simultaneamente, de provocar a interrupção desobediente da diegese conclusiva desta "Terra Prometida", gerando uma miríade de novas narrativas. O "Sonho Americano", não-lugar onde espelhamos os nossos anseios, é, com efeito, muito apelativo, mas o pesadelo é a outra face da mesma moeda. É nesse território submerso de expectativas abortadas que encontramos aquilo que a História não conta. Na dimensão do particular (o "there" do dedo que nos consciencializa) são-nos apresentados dados como os que mostram que os EUA são o país com a maior taxa de encarceração do mundo e que um terço do número de presos, três milhões no total, são negros, como apontou a geógrafa Ruth Wilson Gilmore, actual presidente da Associação Americana de Estudos Americanos. Como Teresa Alves salientou, a relação transnacional com a "América" tende a ser agridoce: uma simbiose de amor e ódio. Contudo, esta nunca deixa de ser "a nossa América" (como o alemão Heinz Ickstadt relembrou, referindo-se à obra epónima do escritor activista cubano José Martí), isto é, algo que nos condiciona (colonizando o nosso imaginário) e, ao mesmo tempo, algo em relação ao qual não devemos enjeitar responsabilidades enquanto agentes imaginativos que exercem uma "cidadania global" e empática. Esta última pressupõe o reconhecimento de um inimigo comum: a cultura imperialista dominante que é, paradoxal e redundantemente, "a nossa América".
A metodologia actual dos Estudos Americanos, caracterizada por uma perspectiva transnacional, requer de nós esse mesmo esforço: que olhemos de fora um território dentro do qual nos movemos e que nunca conseguimos inteiramente abandonar (daí a impossibilidade de uma linguagem não contaminada). Partindo de um denominador comum que privilegie um respeito pela integridade do Outro, podemos, contudo, imaginar uma "América” que queremos que seja excepcional, como salientou Heinz Ickstadt, ele próprio ex-presidente da Associação Europeia de Estudos Americanos.

No entanto, esse não-lugar americano tem também de ser um lugar-não. Parece inevitável que o projecto a partir do qual se arquitecte um mundo melhor tenha de ser capaz de assumir, com modéstia, as limitações que colocam entraves ao nosso conhecimento do Outro. É fulcral que os Estudos Americanos se centrem nos aspectos particulares e estruturais de cada sociedade, de forma a impedir que a perspectiva transnacional se converta numa mera romantização do carácter fluido do espaço da fronteira. É importante, do mesmo modo, proceder a uma consciencialização dos públicos locais, no sentido de promover uma perspectiva crítica que ponha em causa aquilo que o irlandês Liam Kennedy (director do Clinton Institute for American Studies, University College Dublin) descreveu como um mecanismo de reacção que privilegia o escândalo e a passividade em detrimento da interacção e da compaixão. Em suma, a "nossa América" é nada mais nada menos que a "velha América", como o poeta Walt Whitman a havia vestido no século XIX: um espaço poético de combinatórias restritamente ilimitadas que é de todos e, paradoxalmente, de cada um de nós.

João Paulo Guimarães 